\title{
Developing an Ethanol Utilization Pathway based NADH Regeneration System in Escherichia coli
}

\author{
Wenfa Ng \\ Department of Chemical and Biomolecular Engineering, National University of Singapore.
}

*Corresponding Author: Wenfa Ng, Department of Chemical and Biomolecular Engineering, National University of Singapore.

Received date: September 29, 2021; Accepted date: October 12, 2021; Published date: October 28, 2021

Citation: Wenfa Ng (2021) Developing an Ethanol Utilization Pathway based NADH Regeneration System in Escherichia coli. J, Biotechnology and Bioprocessing 2(9); DOI: 10.31579/2766-2314/059

Copyright: ( $)$ 2021,Wenfa Ng, This is an open access article distributed under the Creative Commons Attribution License, which permits unrestricted use, distribution, and reproduction in any medium, provided the original work is properly cited.

\begin{abstract}
Interests remain in searching for cofactor regeneration system with higher efficiency at lower substrate cost. Glucose dehydrogenase (GDH) system has been dominant in NADH regeneration, but it only has a theoretical yield of one NADH per glucose molecule. This work sought to explore the utility of a two-step ethanol utilization pathway (EUP) in pathway-based NADH regeneration. The pathway runs from ethanol to acetaldehyde and to acetyl-CoA with each step generating one NADH, that together results in a higher theoretical yield of two NADH per ethanol molecule. In this project, anaerobic biotransformation of ketone (acetophenone or butanone) to alcohol by cpsADH from Candida parapsilosis was used as readout for evaluating relative efficacy and operating modes for EUP cofactor regeneration in Escherichia coli BL21 (DE3). Experiment tests validated that EUP was more efficient than GDH in NADH regeneration. Further, growing cell delivered higher biotransformation efficiency compared to resting cell due to the driving force generated by cell growth. Finally, preculture or cultivation in M9 $+10 \mathrm{~g} / \mathrm{L}$ ethanol medium delivered higher biotransformation efficiency compared to LB medium. Overall, EUP could help regenerate NADH in support of a biocatalytic reaction, and is more efficient in cofactor regeneration than GDH.
\end{abstract}

Keywords: cofactor regeneration, ethanol utilization, glucose dehydrogenase, biotransformation, whole-cell biocatalysis

\section{Introduction}

Cofactor dependent oxidoreductases play a hugely important role in biocatalysis and biotransformation. Specifically, these enzymes are the pillars on which we could perform difficult organic chemistry kinetic resolution or biotransformation in whole cells under mild conditions compared to harsh conditions used in synthetic organic chemistry [1,2]. Dependence on cofactors naturally meant that provision of expensive cofactors on a stoichiometric basis is necessary for maintaining high product yield. The alternative solution is that of using cofactor regeneration systems to provide needed cofactors for a biotransformation $[3,4]$. Principally, a cofactor regeneration system utilizes an enzyme to convert a sacrificial substrate to a second product that in the process also help regenerate the cofactor needed by the main biotransformation reaction.

As construed, the enzymatic cofactor regeneration system works in tandem with the main biotransformation reaction to help convert the main biotransformation substrate into the target product. Such a system would only work and remain coupled if the rates of the cofactor regeneration reaction is comparable to that of the main biotransformation reaction [5]. But, the main benefit of a cofactor regeneration system is in shifting the cost burden from provision of expensive cofactor to that of the sacrificial substrate, which could be low-cost [6]. Another less often noted concern in cofactor regeneration is the generation of a byproduct that could complicate the downstream separation of the main biotransformation product [6]. Thus, work in the biocatalysis field has been on the search for low-cost sacrificial substrate/enzyme system that could be usefully tapped for cofactor regeneration without posing separation concerns for the main biotransformation product $[7,8]$.

In the area of NADH regeneration, glucose dehydrogenase (GDH) enzyme remains the most popular and dominant [9-12]. Other NADH regeneration systems include formate dehydrogenase [13-15], and NADH oxidase [16-18]. To be effective and useful, a cofactor regeneration system should deliver high yield of cofactor per molecule of substrate, and less often noted, be of relatively fast kinetics. For example, glucose dehydrogenase available in Bacillus species converts glucose to gluconolactone with the generation of one NADH [19]. This meant a cofactor yield of one NADH per glucose molecule. Formate dehydrogenase, on the other hand, converts formate to carbon dioxide with the generation of one NADH [20]. But, the system suffers from potential problem with the acidification of the medium due to carbon dioxide dissolution [21]. Finally, NADH oxidase offers the most tantalizing prospects of a cofactor regeneration system delivering a benign product. Specifically, NADH oxidase uses molecular oxygen to convert $\mathrm{NAD}^{+}$to $\mathrm{NADH}$ with the generation of either $\mathrm{H}_{2} \mathrm{O}_{2}$ or water [22]. 
But, dependence on molecular oxygen meant that NADH oxidase could only operate under aerobic conditions, which restricts its application space in biocatalysis.

Work described in this manuscript sought to demonstrate the NADH cofactor regeneration potential of a two-gene ethanol utilization pathway (EUP) that sequentially converts ethanol to acetaldehyde and on to the growth promoting metabolite, acetyl-CoA. The first step of the pathway is mediated by adh 2 from Saccharomyces cerevisiae with the generation of one NADH [23]. This is followed by the second step of the pathway mediated by ada from Dickeya zeae that generates another NADH [23]. Hence, from the theoretical perspective in this project, EUP generates two $\mathrm{NADH}$ per ethanol molecule, and is more efficient in cofactor regeneration than the glucose dehydrogenase system. More importantly, the two-gene pathway ends in acetyl-CoA, which can be connected to central carbon metabolism, thereby, enabling distribution of ethanol flux to growth processes in growing cell biotransformation, that theoretically, could provide a greater driving force for NADH regeneration. In addition, acetyl-CoA remains in the cell and would not complicate downstream separation of biotransformation product. Finally, lack of oxygen dependence meant that the EUP could operate under both aerobic and anaerobic conditions, which expands the operating envelope of the cofactor regeneration system. This project sought to convert ethanol to acetyl-CoA with NADH regeneration that could be usefully tapped for biocatalysis.

In theory, cofactor regeneration could be implemented in vitro or in vivo [24]. The latter is more attractive as whole-cell biocatalysis delivers better performance after issues such as enzyme cost and stability are taken into account [25]. This project chose Escherichia coli to implement a whole cell biocatalytic system. The coupling biotransformation reaction is chosen as the ketone to alcohol biotransformation mediated by a proven NADH-dependent alcohol dehydrogenase (cpsADH) from Candida parapsilosis [26]. Two substrates, acetophenone (hydrophobic) and butanone (hydrophilic) are chosen in this project to test the utility of EUP in regenerating NADH under circumstances of a two-phase or single aqueous phase biotransformation system common in biocatalysis.

Experimental results collected in this project revealed that E. coli harbouring the EUP pathway could grow on ethanol, which meant that the two-step EUP pathway is functional. More importantly, in biotransformation assays converting butanone to 2-butanol, product yield was enhanced with use of EUP relative to glucose/GDH system. This validated theoretical predictions that the EUP pathway is more efficient in regenerating NADH compared to glucose/GDH system. Furthermore, growing cells were shown to enable higher biotransformation efficiency compared to resting cells presumably due to the driving force generated by cell growth that push ethanol flux to acetyl-CoA. Finally, gene expression pattern resultant from cultivation in different growth media either prior to or during biotransformation also impact on biotransformation efficiency. In this case, M9 medium supplemented with $10 \mathrm{~g} / \mathrm{L}$ ethanol was shown to enable higher biotransformation efficiency compared to LB medium in both resting cell and growing cell biotransformation.

The overall picture that emanates from the experimental results collected in this project point to ethanol utilization as a viable platform for regenerating NADH in whole cell biocatalysis converting either acetophenone to 1-phenylethanol or butanone to 2-butanol in E. coli. Given that it is a plasmid-based platform, the two-gene EUP pathway could be readily transplanted to other species for enabling NADH regeneration in support of a NADH requiring biotransformation reaction. Although EUP is more efficient than the state-of-the-art GDH system in regenerating $\mathrm{NADH}$, higher cost of ethanol may still tilt the balance in favour of GDH system. The aim of this article is to describe the experiment work that validated the utility of EUP as a cofactor regeneration system for $E$. coli in biocatalysis applications, and some of its operational dependencies and characteristics.

\section{Materials and Methods}

\subsection{Chemicals and medium composition}

LB medium was purchased from Difco and used as is. Composition of LB medium was $(\mathrm{g} / \mathrm{L})$ : Tryptone, 10.0; $\mathrm{NaCl}, 10.0$; Yeast extract, 5.0. Composition of potassium phosphate buffer was $(\mathrm{g} / \mathrm{L})$ : $\mathrm{K}_{2} \mathrm{HPO}_{4}, 12.54$; $\mathrm{KH}_{2} \mathrm{PO}_{4}$, 2.31. Composition of modified M9 medium was (g/L); $\mathrm{K}_{2} \mathrm{HPO}_{4}$, 6.8; $\mathrm{KH}_{2} \mathrm{PO}_{4}, 3.0 ; \mathrm{NH}_{4} \mathrm{Cl}, 1.0 ; \mathrm{NaCl} ; 2.0$; Yeast extract, 1.0; Ethanol, 10.0. Composition of high cell density medium was $(\mathrm{g} / \mathrm{L}): \mathrm{K}_{2} \mathrm{HPO}_{4}$, 12.54; $\mathrm{KH}_{2} \mathrm{PO}_{4}, 2.31 ; \mathrm{D}-G l u c o s e, 4.0 ; \mathrm{NH}_{4} \mathrm{Cl}, 1.0 ; \mathrm{NaCl} ; 5.0$; Yeast extract, 12.0; $\mathrm{MgSO}_{4}, 0.24$. Antibiotics used were ampicillin $(100 \mu \mathrm{g} / \mathrm{mL})$ and spectinomycin $(50 \mu \mathrm{g} / \mathrm{mL})$. Acetophenone, 1-Phenylethanol, glucose, butanone, 2-butanol, n-hexadecane and ethyl acetate were of analytical reagent grade $(99 \%)$ and purchased from Sigma Aldrich.

\subsection{Plasmid construction}

Ethanol utilization pathway comprises two genes: adh2 and ada were placed under the control of an autoinducible promoter, $\mathrm{P}_{\text {thrC3 } 3}$ and inserted into a plasmid backbone with ampicillin as antibiotic resistance marker. Adh2 was cloned from Saccharomyces cerevisiae and ada was cloned from Dickeya zeae by my labmate, Ms Liang Hong, from whom I inherited the initial pathway. pMB1 serves as the origin of replication in this plasmid. On the other hand, cpsADH alcohol dehydrogenase enzyme was cloned from Candida parapsilosis and placed under the control of an autoinducible promoter, $\mathrm{P}_{\mathrm{thr} C}$, and inserted into a plasmid backbone with spectinomycin antibiotic resistance marker. I inherited this plasmid from Mr. Liu Hongyuan from the lab. The replication origin of this plasmid is pA15. Given their differing antibiotic resistance marker and replication origin, both plasmids could be stably maintained in E. coli BL21 (DE3). Both plasmids were transformed into Escherichia coli BL21 (DE3) using standard heat shock transformation method.

\subsection{General procedure for cloning of genes from bacterial species}

Glucose dehydrogenase (gdh, Bacillus subtilis), aldehyde dehydrogenase (aldA, E. coli) and alcohol/aldehyde dehydrogenase (adhE, E. coli) were cloned from their respective bacterial species. Using appropriate primers, the respective genes were cloned through colony PCR in the thermocycler (Biorad, T-100). Specifically, $1 \mu \mathrm{L}$ of a 16 hour bacterial culture in LB Miller medium was used as template for PCR amplification. PCR cycling conditions were: $98{ }^{\circ} \mathrm{C}$ for 5 mins, followed by 34 cycles of $\left(98{ }^{\circ} \mathrm{C}\right.$ for 8 $\mathrm{sec}, 55^{\circ} \mathrm{C}$ for $15 \mathrm{sec}$, and $72{ }^{\circ} \mathrm{C}$ for $120 \mathrm{sec}$ ), with final extension of 72 ${ }^{\circ} \mathrm{C}$ for 5 mins. The PCR product was clean-up through gel electrophoresis ( $130 \mathrm{~V}$ for 30 mins, Biorad power pack) followed by gel purification using Thermo Fisher Scientific gel purification kit (GeneJet Gel Extraction Kit, Cat No: \#0692). The resulting gene fragment was ligated with the plasmid backbone using a ligase-free ligation method developed in the lab that includes incubation with $10 \mathrm{mM} \mathrm{MgCl} 2$ in a thermocycling step in a PCR thermocycler (Biorad, T-100). The cycling programme was as follows: 80 ${ }^{\circ} \mathrm{C}$ for $1 \mathrm{~min}, 68^{\circ} \mathrm{C}$ for $10 \mathrm{mins}$, and infinite hold at $4{ }^{\circ} \mathrm{C}$. DNA assembly method used was developed in the lab and is known as the GT standard [27].

After plasmid ligation, colony PCR with appropriate primers were used to confirm ligation of gene fragment with plasmid backbone. Amplified gene fragment was extracted and purified with a gel purification kit (GeneJet Gel Extraction Kit, Cat No: \#0692). Sequence of the gene fragment was verified by Sanger sequencing (BioBasic Singapore). Primers used for the experiments are as listed in Supplementary Table 1 below. 


\begin{tabular}{|c|c|c|}
\hline Gene & Primer Name & Sequence \\
\hline GDH & Glucose dehydrogenase-Forward & 5'-tatccggatttaaaaggaaaagtcgtcgc-3' \\
\hline GDH & Glucose dehydrogenase-Reverse & 5'-accgcggcctgcctggaa-3' \\
\hline aldA & Aldehyde dehydrogenase-Forward & 5'-tcagtacccgttcaacatcctatgtatat-3' \\
\hline aldA & Aldehyde dehydrogenase-Reverse & 5'-ttaagactgtaaataaaccacctgggtct-3' \\
\hline adhE & Alcohol dehydrogenase-Forward & 5'-gctgttactaatgtcgctgaacttaac-3' \\
\hline adhE & Alcohol dehydrogenase-Reverse & 5'-ttaagcggattttttcgctttttctcag-3' \\
\hline
\end{tabular}

Supplementary Table 1: Primers used in the ethanol cofactor regeneration project

\subsection{Cell cultivation}

E. coli was inoculated in $10 \mathrm{~mL} \mathrm{LB}$ medium with $100 \mu \mathrm{g} / \mathrm{mL}$ ampicillin and $50 \mu \mathrm{g} / \mathrm{mL}$ spectinomycin in $125 \mathrm{~mL}$ shake flask. Incubation conditions were $37^{\circ} \mathrm{C}$ and $225 \mathrm{rpm}$ for all cultivations. The incubator used was N-Biotek NB-205 Incubator-shaker. After 5 hours of cultivation, 0.25 $\mathrm{mL}$ of seed culture served as inoculum for $25 \mathrm{~mL}$ of $\mathrm{LB}$ medium with antibiotics in a $125 \mathrm{~mL}$ shake flask and the experiment cultures were cultivated for 20 hours. Optical density of the culture broth was measured at $600 \mathrm{~nm}$ with a UV-Visible spectrophotometer (Ambersham Biosciences). Appropriate dilution with deionized water was performed for samples with absorbance that exceed 1. Cells were harvested for biotransformation by centrifugation at $3300 \mathrm{~g}$ for 5 minutes. Subsequently, cells were resuspended with $89 \mathrm{mM}$ potassium phosphate buffer for a washing step, which included centrifugation at $3300 \mathrm{~g}$ for 5 minutes. Cells were finally resuspended in $89 \mathrm{mM}$ potassium phosphate buffer with a factor of 2 concentration in optical density for resting cell biotransformation. In growing cells biotransformation, cells were not washed with potassium phosphate buffer but were transferred into either LB Miller medium or M9 ethanol medium with a factor of 0.1 in optical density.

\subsection{Acetophenone biotransformation}

Given the poor solubility of acetophenone and 1-Phenylethanol in water, a two-phase system comprising n-hexadecane and potassium phosphate buffer was used in biotransformation. Specifically, either 5 or $20 \mathrm{~g} / \mathrm{L}$ acetophenone was dissolved in $0.5 \mathrm{~mL}$ of $\mathrm{n}$-hexadecane, while $0.5 \mathrm{~mL}$ of potassium phosphate buffer contained $E$. coli cells and $10 \mathrm{~g} / \mathrm{L}$ ethanol. The reaction mixture was contained in $2.0 \mathrm{~mL}$ HPLC vial and incubated anaerobically at $37^{\circ} \mathrm{C}$ and $225 \mathrm{rpm}$ for 20 hours. Duplicate experiments were carried out. Cells were precultivated in LB medium for resting cells experiments.

At suitable time-points, HPLC vials were removed from the incubator. The contents were transferred to a $1.5 \mathrm{~mL}$ microcentrifuge tube and centrifuged at $20000 \mathrm{~g}$ for 2 minutes. The upper organic phase containing the substrate and product was aliquoted and diluted with ethyl acetate prior to gas chromatography-mass spectrometry (GC-MS) analysis for detecting acetophenone and 1-Phenylethanol. Following that, the organic phase was carefully removed by pipetting; thereby, leaving behind an aqueous phase where $200 \mu \mathrm{L}$ was aliquoted, filtered through a $0.22 \mu \mathrm{m}$ nylon filter prior to high performance liquid chromatography (HPLC) analysis for detecting ethanol and acetate.

The performance measure selected for this segment of the work is yield per unit optical density, and is as defined below:

$$
\text { Yield per unit } O D=\frac{\text { Final Phenylethanol conc. }}{\text { Initial acetophenone conc. }- \text { Final acetophenone conc. }} \times \frac{100}{\text { Final optical density }}
$$

\subsection{Butanone biotransformation}

Since butanone and 2-butanol are highly water soluble, only a singlephase biotransformation system is required. Specifically, $10 \mathrm{~g} / \mathrm{L}$ of butanone is added to either potassium phosphate buffer (resting cells) or growth medium (growing cells) together with $10 \mathrm{~g} / \mathrm{L}$ of glucose or ethanol for biotransformation. Concentrations of butanone and ethanol were titrated in experiments aimed at understanding the effect of substrate toxicity effect or whether provision of higher ethanol concentration would drive higher biotransformation efficiency, respectively. The reaction mixture was contained in $2.0 \mathrm{~mL}$ HPLC vial and incubated anaerobically at $37{ }^{\circ} \mathrm{C}$ and $225 \mathrm{rpm}$ for 44 hours. Triplicate experiments were carried out.

At suitable time-points, HPLC vials were removed from the incubator. The contents were transferred to a $1.5 \mathrm{~mL}$ micro centrifuge tube and centrifuged at $20000 \mathrm{~g}$ for 2 minutes. $200 \mu \mathrm{L}$ of the supernatant was aliquoted, filtered through a $0.22 \mu \mathrm{m}$ nylon filter prior to high performance liquid chromatography (HPLC) analysis for detecting, butanone, butanol, ethanol or glucose and acetate.

The performance measure selected for this segment of the work is yield per unit optical density, and is as defined below:

$$
\text { Yield per unit } O D=\frac{\text { Final butanol conc. }}{\text { Initial butanone conc. }- \text { Final butanone conc. }} \times \frac{100}{\text { Final optical density }}
$$

\subsection{Gas chromatography mass spectrometry and high performance liquid chromatography analysis}

Gas chromatography mass spectrometry was used in analysing the concentration of acetophenone and 1-Phenylethanol in Agilent 7890 GC and Agilent 5977B MSD. Injection volume used was $1 \mu \mathrm{L}$ and the oven temperature profile used was $50{ }^{\circ} \mathrm{C}$ for $1 \mathrm{~min}$, ramp from 50 to $180{ }^{\circ} \mathrm{C}$ at $10{ }^{\circ} \mathrm{C} / \mathrm{min}$, followed by another ramp from 180 to $280{ }^{\circ} \mathrm{C}$ at $50{ }^{\circ} \mathrm{C} / \mathrm{min}$ and a hold at $280{ }^{\circ} \mathrm{C}$ for 3 minutes. MS detector was turned off at 13 minutes to protect the mass spectrometry detector.
High performance liquid chromatography was conducted with an Agilent 1260 series instrument equipped with a Bio-rad Aminex HPX-87H column. $5 \mu \mathrm{L}$ of sample was injected into the column and eluted with 5 $\mathrm{mM}$ sulphuric acid at $0.7 \mathrm{~mL} / \mathrm{min}$. Isocratic elution was used and the column was maintained at $50{ }^{\circ} \mathrm{C}$. Analytes were detected by a refractive index detector.

\subsection{Data analysis and statistical methods}

Experiments were conducted in triplicate, and the average of the three 
measurements is reported. Experimental error is quantified via the average deviation approach, which measures the average deviation of each measurement from the average value.[28]
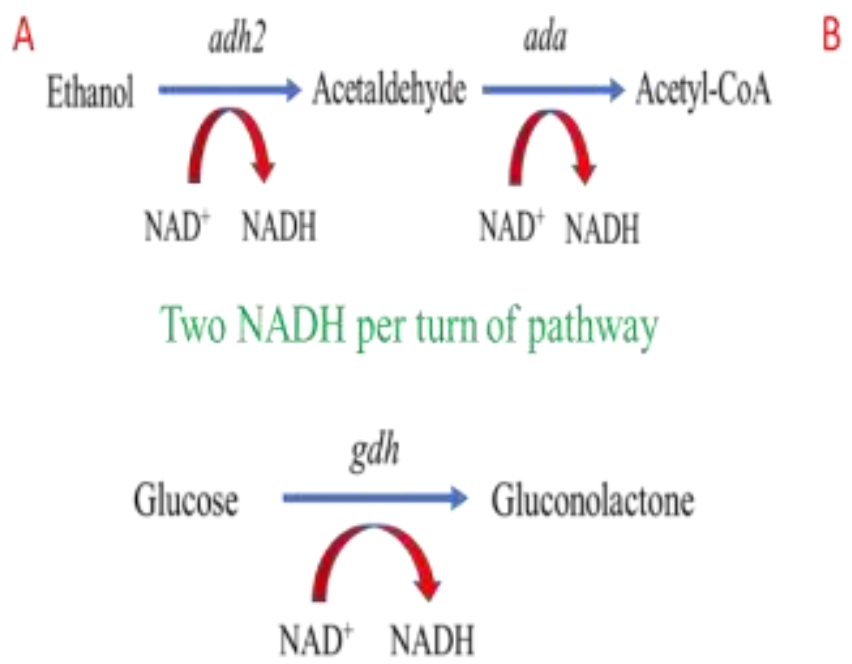

One NADH per turn of pathway

\section{Results}

B

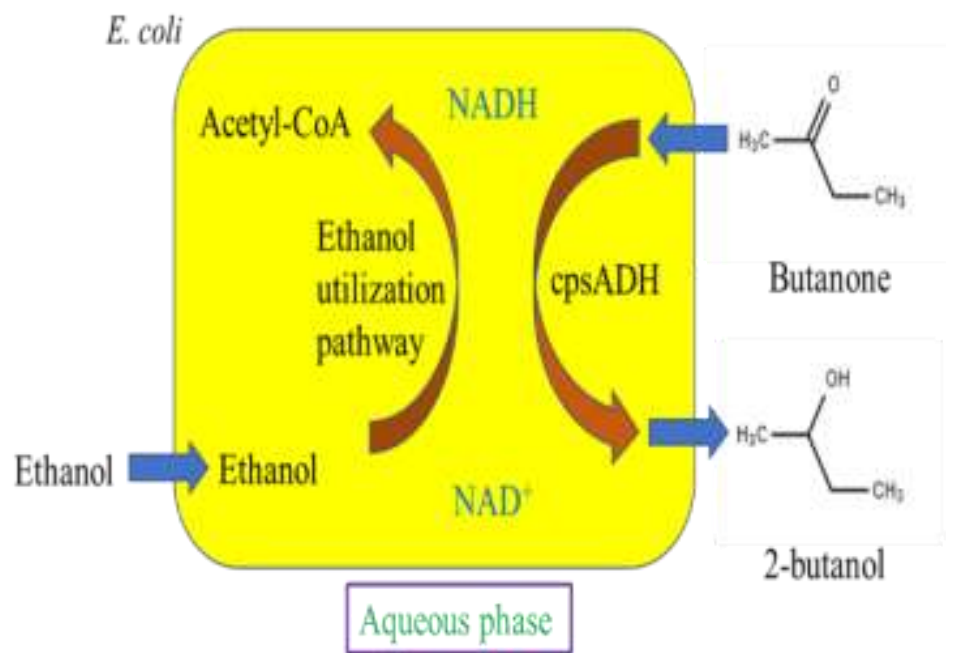

Figure 1. Conceptual basis of ethanol utilization pathway (EUP) and whole cell biocatalysis. A) Ethanol utilization pathway delivers higher NADH regeneration capability compared to glucose dehydrogenase system, B) Integration of EUP with cpsADH in an Escherichia coli BL21 (DE3) whole cell biocatalytic system.

At the theoretical level, the two gene ethanol utilization pathway (EUP) delivers one NADH per step of the pathway that culminates in two NADH generated per ethanol molecule. This is a $100 \%$ improvement over the competing glucose dehydrogenase $(\mathrm{GDH})$ system which regenerates one NADH per glucose molecule (figure 1a). Hence, theoretically, the EUP pathway is more efficient than GDH in regenerating NADH.

To be effective, the EUP pathway must be integrated with cpsADH in a whole cell biocatalytic system with E. coli BL21 (DE3) as microbial chassis. Specifically, the two gene EUP pathway is encoded on a plasmid with pthrC3 auto inducible promoter, while cpsADH enzyme is encoded on another plasmid with pthrC3 auto inducible promoter. The whole cell biocatalytic system works by up taking ethanol and converting it into acetyl-CoA with the generation of two NADH per ethanol molecule. At the same time, butanone or acetophenone would be taken up by the cell and converted by the NADH dependent cpsADH into alcohol which is secreted out of the cell (figure 1b). Amount of 2-butanol or 1- phenylethanol produced would be taken as yardstick to assess the biotransformation efficiency of the cofactor regeneration system.

EUP ends with acetyl-CoA, which is a growth promoting metabolite. Thus, if the pathway is functional, provision of ethanol in M9 medium should engender growth. Experimental results in M9 + $10 \mathrm{~g} / \mathrm{L}$ ethanol medium reveals that the EUP pathway was functional and could support growth of E. coli ethcps 2 under aerobic conditions. Specifically, rapid growth of $E$. coli ethcps2 during exponential phase coincided with ethanol utilization (Supplementary figure S1a). Similarly, E. coli ethcps 2 could attain appreciable growth in M9 ethanol medium under anaerobic conditions at $37{ }^{\circ} \mathrm{C}$ and $225 \mathrm{rpm}$. This is consistent with theoretical predictions in this study that the EUP pathway genes would be expressed under anaerobic conditions and that the enzymes are not dependent on oxygen for function. More significantly, E. coli ethcps 2 could attain comparable growth in M9 medium supplemented with either $10 \mathrm{~g} / \mathrm{L}$ glucose or ethanol (Supplementary figure S1b). 

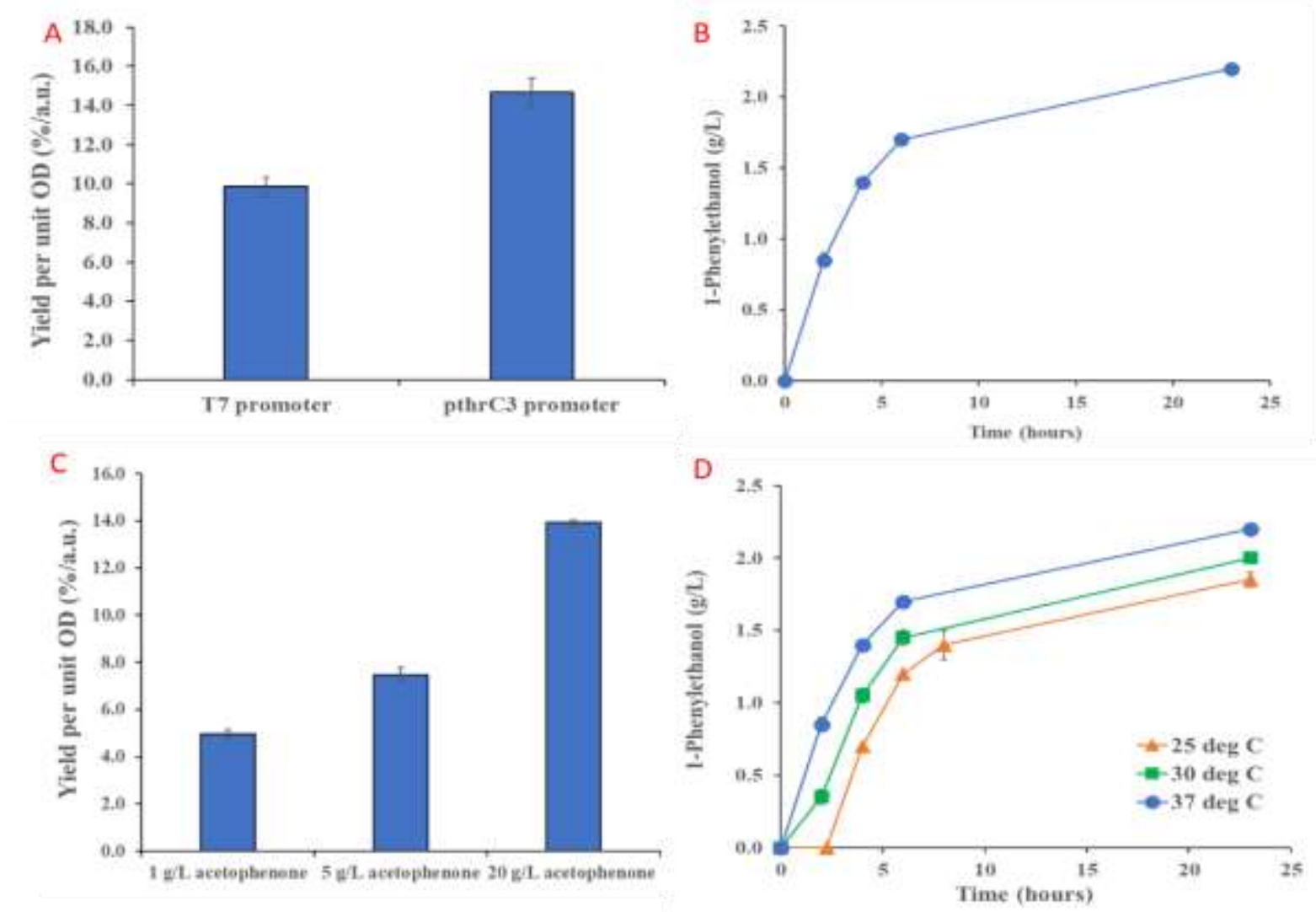

Figure 2. EUP could support acetophenone biotransformation in E. coli in a two phase system. A) Autoinducible pthrC3 promoter delivered higher
biotransformation efficiency compared to T7 promoter in E. coli microbial chassis at 37 oC and 225 rpm in resting cells anaerobic
biotransformation, B) Formation of 1 -Phenylethanol product was rapid in the first few hours of the biotransformation, but tapered towards the latter
stage of the process, C) Yield per unit OD improved with increase in acetophenone substrate concentration, thereby, indicating that the n-
hexadecane organic phase could store and ameliorate potential toxicity effect from elevated acetophenone concentration, D) Higher incubation
temperature favoured the formation of more 1-Phenylethanol product and greater biotransformation efficiency.

The first part of the project concerns the integration of the EUP cofactor regeneration system with cpsADH enzyme as a whole-cell biocatalytic system suited for the biocatalytic conversion of ketone to alcohol. Acetophenone, a hydrophobic substrate, would be the first substrate to be tested. To be useful, a promoter needs to drive the transcription and expression of EUP genes. In this project, a synthetic T7 promoter commonly used in biotechnology and an auto inducible pthrC3 promoter from $E$. coli are evaluated. As this was a resting cell experiment, E. coli cells harbouring EUP plasmid with T7 promoter were induced with 0.1 mM IPTG 3 hrs into cell cultivation. Experimental results revealed that biotransformation efficiency of acetophenone to 1-phenylethanol biotransformation was higher when EUP genes were under the control of pthrC3 compared to $\mathrm{T} 7$ promoter (figure $2 \mathrm{a}$ ). This came about presumably due to the higher expression of genes under the control of auto inducible pthrC3 promoter compared to $\mathrm{T} 7$ promoter.

Kinetics of biotransformation is a hugely important parameter that governs the industrial feasibility of a given reaction. Experimental data in figure $2 \mathrm{~b}$ showed that the acetophenone to 1-phenylethanol biotransformation was quite rapid in the first few hours, but reaction slowed towards latter part of the reaction. This points to possible equilibrium control of the biotransformation reaction as cpsADH is a reversible enzyme able to catalyze both directions of the biotransformation reaction. Next, acetophenone substrate loading experiments were carried out to determine the extent in which the approach would help push the reaction forward towards product formation. Data revealed that higher biotransformation efficiency was obtained with higher acetophenone loading moving from $1 \mathrm{~g} / \mathrm{L}$ to $20 \mathrm{~g} / \mathrm{L}$ acetophenone (figure 2c). Importantly, no substrate toxicity effect was observed due to the n-hexadecane phase serving as a reservoir for acetophenone, which only allows small amount (solubility limit) of the substrate to come into contact with cells. Finally, efforts to reduce the process temperature to either 30 or $25{ }^{\circ} \mathrm{C}$ showed that this was not possible. In particular, product yield and biotransformation efficiency improved in a monolithic fashion with incubation temperature moving from 25 to $37^{\circ} \mathrm{C}$ (figure $2 \mathrm{~d}$ ). 

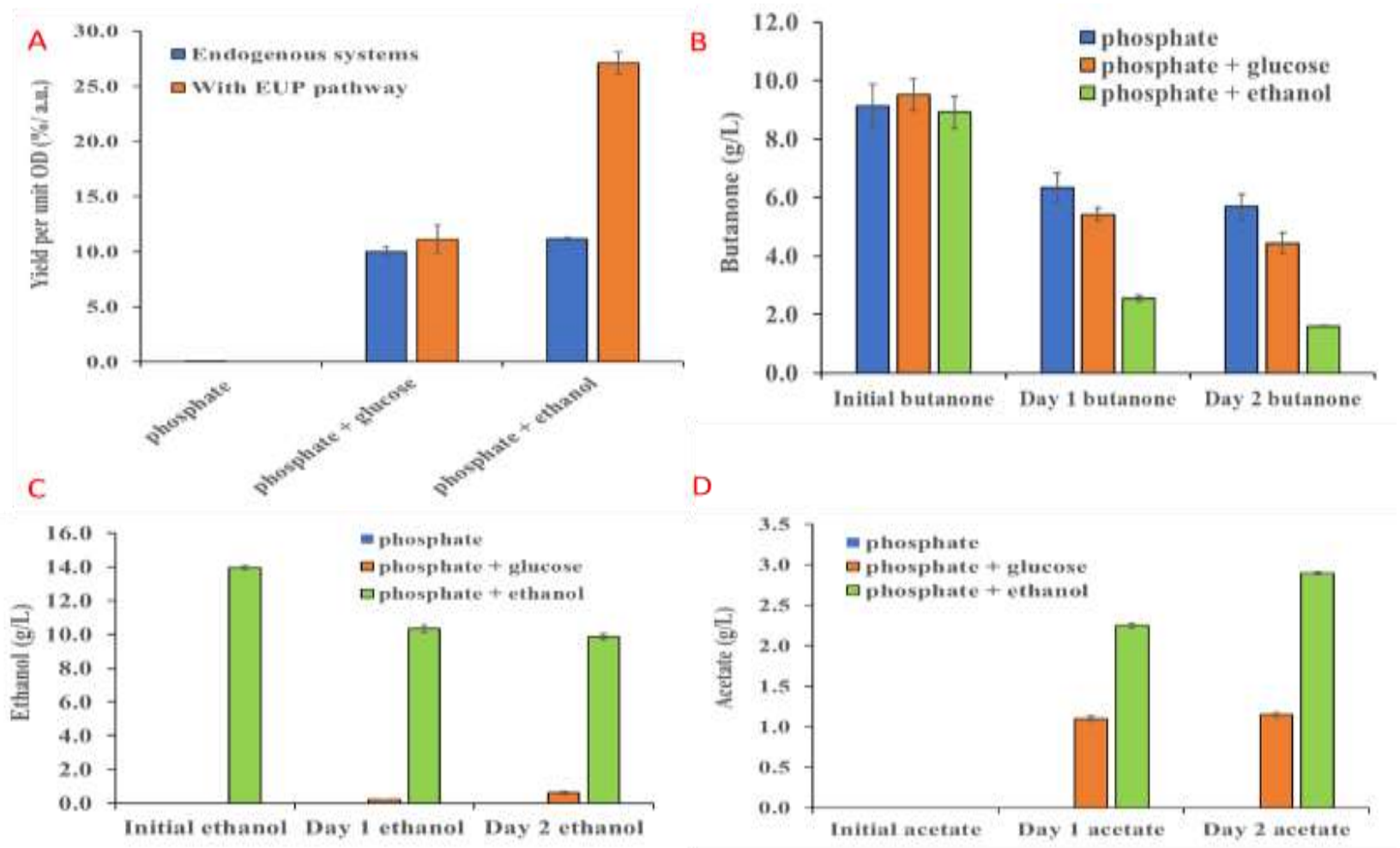

Figure 3. EUP enabled butanone biotransformation in single phase system in resting cells precultivated in $M 9+10 \mathrm{~g} / \mathrm{L}$ ethanol medium at $37 \mathrm{oC}$ and $225 \mathrm{rpm}$. A) EUP pathway delivered higher biotransformation efficiency compared to endogenous glucose and ethanol metabolization systems,

B) Butanone consumption was highest in cells fed with ethanol, thereby, indicating a correlation between NADH regeneration and butanone utilization, C) Ethanol utilization was poor over the two day incubation period, which points to room for engineering higher ethanol utilization, D) Acetate formation was highest in cells fed with ethanol, which indicates that acetyl-CoA conversion to acetate is a major route for channelling ethanol pathway flux in resting cells.

Work subsequently moved to determine the efficacy in which the EUP pathway could support a ketone to alcohol biotransformation reaction in single aqueous phase. Butanone is the substrate chosen due to its hydrophilic nature, and where the corresponding product, 2-butanol is a useful biofuel. Resting cells equipped with both EUP and cpsADH (i.e., E. coli ethcps2) were cultivated in $\mathrm{M} 9+10 \mathrm{~g} / \mathrm{L}$ ethanol medium. E. coli cells without EUP but with cpsADH (i.e., E. coli cps2) was used to examine the ability of the endogenous ethanol and glucose utilization pathways in regenerating NADH. In all experiments, glucose was the reference substrate to serve as positive control as provide comparison for the relative utility of EUP and endogenous ethanol utilization system in regenerating $\mathrm{NADH}$.

Experiment results revealed that EUP could support butanone biotransformation to 2-butanol through regeneration of NADH. For comparison, the yield per unit OD of cells with EUP was 2 times that of cells with endogenous ethanol utilization system (figure 3a). More importantly, endogenous ethanol and glucose utilization systems delivered similar biotransformation efficiency. Overall, the results suggest that the EUP pathway was functional and could support a whole cell biocatalytic reaction converting butanone to 2-butanol. HPLC analysis of metabolite concentration revealed that cells fed with ethanol also had the highest butanone uptake and utilization (figure 3b). This suggests a correlation between NADH regeneration and butanone consumption. Next, profile of ethanol utilization efficiency revealed a large residual amount of ethanol in the system after 2 days of incubation, with only $2-3 \mathrm{~g} / \mathrm{L}$ of ethanol utilized (figure $3 \mathrm{c}$ ). The data also suggests a possible fundamental constraint in ethanol utilization that could likely be associated with anaerobic biotransformation conditions. For resting cells,
acetyl-CoA could accumulate as there is a lack of growth processes that siphon off the produced acetyl-CoA. But, experimental data suggests that acetate may be the final product of EUP operation in resting cells given its relatively high titer and progressive increase in concentration with incubation time (figure 3d). What likely transpires may be that acetylCoA from EUP was transformed to acetate through acetyl-phosphate.

Efforts were also directed towards tuning parameters such as ethanol and butanone concentration to improve biotransformation efficiency. This arises because both the EUP pathway and cpsADH power reversible reactions. To improve NADH regeneration and product formation, ethanol and butanone concentration would need to be increased to push the equilibrium position forward towards product formation. In terms of ethanol provision, experiment results elucidated a positive correlation between ethanol concentration and biotransformation efficiency for resting cells (Supplementary figure S2a). This indicates that higher ethanol concentration pushes flux towards acetyl-CoA in EUP and results in higher regeneration of NADH. However, such positive correlation was not observed in growing cell biotransformation where $10 \mathrm{~g} / \mathrm{L}$ ethanol exerted some cellular toxicity. On the other hand, high substrate loading is always desired in biotransformation reactions to improve product titer. In this area, data revealed a clear substrate toxicity effect from single phase biotransformation (Supplementary figure S2b). Specifically, higher butanone concentration resulted in a decline in biotransformation efficiency for resting cells precultivated in either $\mathrm{LB}$ or $\mathrm{M} 9+10 \mathrm{~g} / \mathrm{L}$ ethanol medium. Such toxicity effect could arise from the elevated butanone concentration experienced by the cells during biotransformation. 

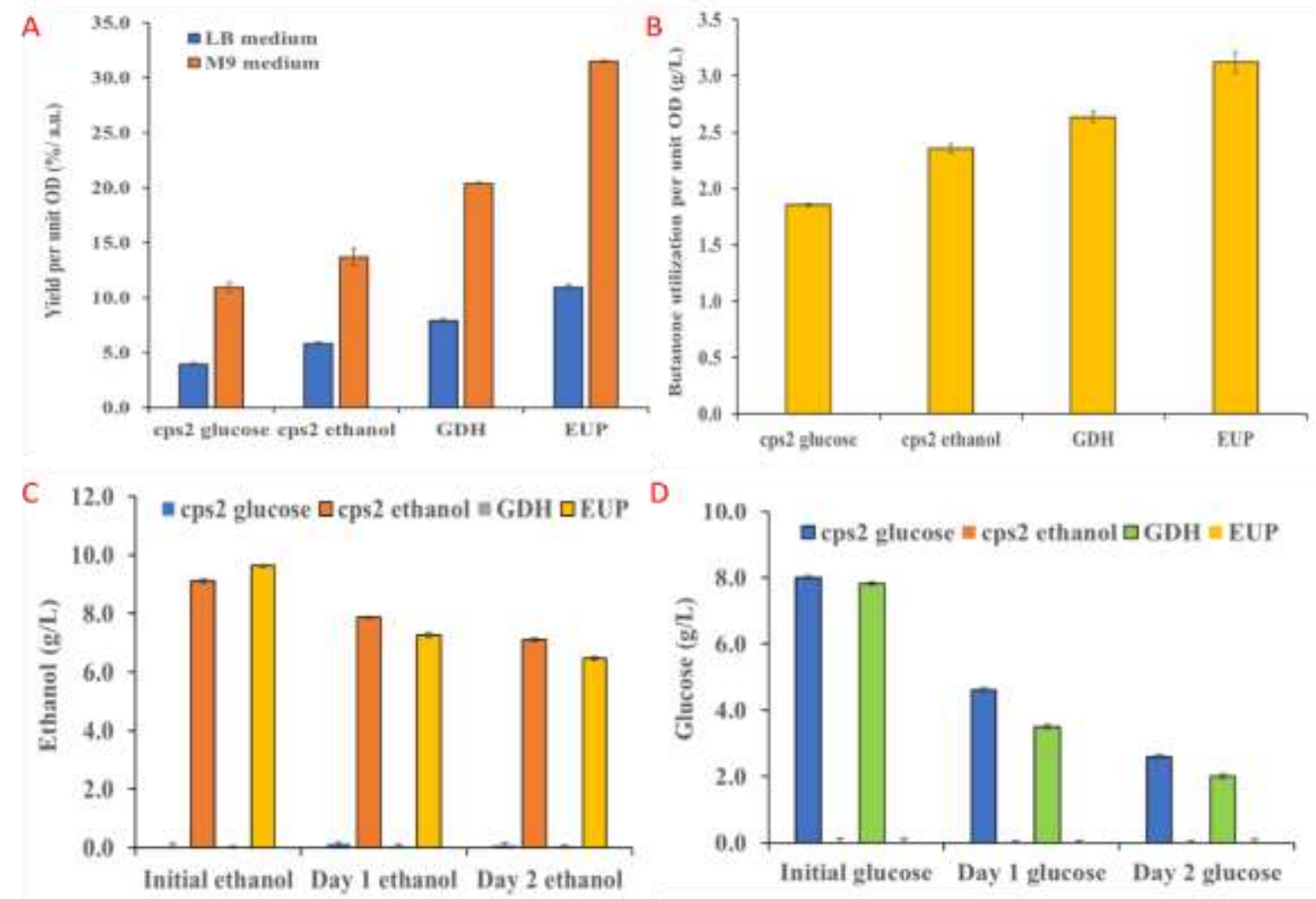

\begin{abstract}
Figure 4. Comparison of biotransformation efficiency of EUP and GDH in resting cells with either $10 \mathrm{~g} / \mathrm{L}$ glucose or $10 \mathrm{~g} / \mathrm{L}$ ethanol as co-substrates at $37 \mathrm{oC}$ and $225 \mathrm{rpm}$ under anaerobic conditions. A) EUP delivered higher biotransformation efficiency compared to GDH irrespective of the growth medium in which the resting cells were precultivated, B) Butanone utilization per unit OD showed the same trend as yield per unit OD across the different categories tested in resting cells precultivated in $M 9+10 \mathrm{~g} / \mathrm{L}$ ethanol medium, which suggests that amount of NADH regenerated drives butanone utilization, C) Cells with EUP pathway utilized more ethanol compared to cells with endogenous ethanol utilization system (E. coli cps2), which indicates that heterologous EUP was expressed and was functional, D) More glucose was consumed by cells with GDH compared to cells with endogenous glucose utilization system (E. coli cps2). Inability to fully utilize glucose over 2 days meant that a fundamental limit may exist in glucose utilization under anaerobic conditions which precludes loading of more glucose into the biotransformation system to enable equimolar comparisons between the two substrates. Data for C and D were obtained from resting cells precultivated in $M 9+10 \mathrm{~g} / \mathrm{L}$ ethanol medium.
\end{abstract}

Prior experiments have demonstrated the utility of EUP in regenerating $\mathrm{NADH}$ in support of a ketone to alcohol biotransformation occurring in E. coli BL21 (DE3) whole cells. But, we do not yet know its relative efficacy in regenerating NADH and promoting biotransformation compared to other systems such as glucose dehydrogenase (GDH). Thus, work started in this project to clone GDH from Bacillus subtilis to serve as comparison for the EUP system. GDH gene was successfully cloned by PCR and inserted into the same vector as EUP under the control of the same autoinducible pthrC3 promoter to afford fair comparison between the two NADH regeneration systems. Similar to EUP, the plasmid encoding GDH was co-transformed with plasmid encoding cpsADH into E. coli BL21 (DE3) to constitute strain E. coli GDHcps1 for biotransformation.

In resting cells experiment with $E$. coli cps 2 fed with either $10 \mathrm{~g} / \mathrm{L}$ glucose or $10 \mathrm{~g} / \mathrm{L}$ ethanol as controls, EUP pathway delivered higher biotransformation efficiency compared to GDH irrespective of whether LB or M9 + $10 \mathrm{~g} / \mathrm{L}$ ethanol was used for precultivation (figure $4 \mathrm{a}$ ). Such data corroborate theoretical reasonings that EUP would deliver higher NADH regeneration efficiency compared to GDH as EUP regenerates two NADH molecule per ethanol molecule compared to GDH regeneration of one NADH per glucose molecule. At the same time, both GDH and EUP delivered higher biotransformation efficiency compared to their respective endogenous glucose or ethanol utilization systems, which indicated that heterologous expression of GDH and EUP were successful and both cofactor regeneration systems were functional. Butanone utilization per unit OD also provided useful yardsticks for assessing the relative performance of GDH and EUP. Specifically, data revealed that butanone utilization was higher for cells with EUP compared to those with GDH (figure 4b). This suggests that NADH regeneration efficiency is intimately tied to butanone consumption, which higher NADH regeneration driving higher butanone consumption.

To compare the relative efficiency of two NADH regeneration systems require fair comparison of their substrate utilization. This then require equal amount of glucose or ethanol to be provided to the cells under the molar basis. But data from figure $4 \mathrm{c}$ and figure $4 \mathrm{~d}$ concerning glucose and ethanol utilization imply that the above idea may not be possible in this system. Specifically, glucose could not be completely consumed over 2 days, which suggests a fundamental limit to glucose consumption may exist in the system. Such a situation then precludes the use of equimolar concentration of glucose and ethanol for determining the relative efficiency of GDH and EUP cofactor regeneration system. The data collected suggests that ethanol utilization with EUP may be a better NADH regeneration system compared to glucose utilization with GDH after considering substrate consumption by cells in a whole cell biocatalytic system. Overall, the data and analysis reported here points to the need to consider limitations in substrate uptake by cells during comparison of relative efficiency of different cofactor regeneration systems in whole cell biocatalysis systems. 

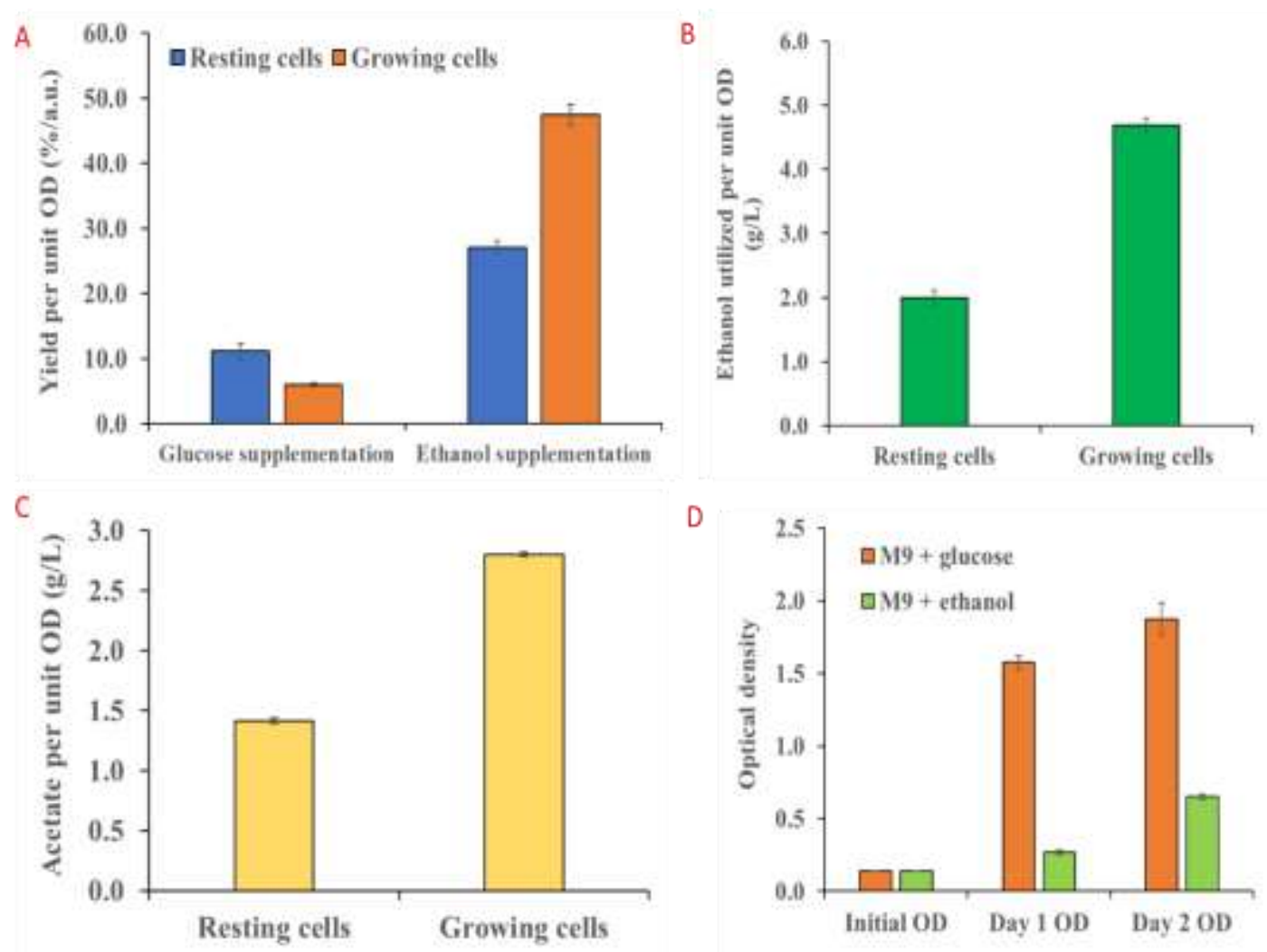

Figure 5. Comparison between the biotransformation efficiency achievable for resting and growing cells either precultivated or grown in M9 +10 g/L ethanol medium. A) Growing cells delivered a higher biotransformation efficiency over resting cells for those fed with ethanol, B) Ethanol utilization per unit $O D$ was also higher for growing cells than resting cells, bearing testament to the effect of driving force from cell growth that led to increased ethanol consumption and NADH regeneration, C) Acetate formation per unit OD was also higher for growing cells compared to resting cells, which confirms that growing cells drove greater flux from ethanol to acetyl-CoA and on to acetate through acetyl-phosphate, D) Cells could grow in $M 9+10 \mathrm{~g} / \mathrm{L}$ ethanol medium during growing cell biotransformation, but growth was retarded probably due to toxicity of butanone. All experiments conducted in this series were performed under anaerobic conditions at $37 \mathrm{oC}$ and $225 \mathrm{rpm}$.

Growing cells have been used in many areas of metabolic engineering to drive flux down a designated metabolic pathway to deliver higher product yield. This approach relies heavily on engineering particular nodes or intermediates to be coupled to cell growth, which would subsequently drive flux to move towards the engineered nodes in the metabolic network. In this project, the EUP pathway ends at acetyl-CoA, which is a natural growth promoting metabolite; thus, cell growth should be able to draw flux from acetyl-CoA for building biomass, and hence, help move flux from ethanol to acetyl-CoA that helps regenerate more NADH in support of biotransformation.

Experiment data verified theoretical predictions that growing cell should deliver a higher biotransformation efficiency compared to resting cells (figure 5a). But, what is of greater interest is the confirmation, from metabolite utilization and production data, that indeed, growing cells delivered a driving force to improve carbon flux from ethanol to acetyl$\mathrm{CoA}$ and help improve NADH regeneration in support of biotransformation. To do this, both ethanol utilization and acetate formation was monitored by HPLC. In particular, ethanol utilization per unit OD revealed that growing cells helped improve ethanol consumption compared to resting cells (figure 5b). This result validates that growing cells could improve ethanol utilization by forcing flux to move down the EUP pathway. At the other end of the pathway, observations of increased acetate formation per unit OD in growing cells compared to resting cells again validated that cell growth drove flux from ethanol to acetyl-CoA which is converted to acetate through acetyl-phosphate (figure 5c). Part of the reason there was high acetate concentration in growing cells despite channelling of acetyl-CoA flux to cell growth in growing cell biotransformation could be the limited cell growth in $\mathrm{M} 9+10 \mathrm{~g} / \mathrm{L}$ ethanol medium (figure 5d). Such limited growth is opposite to observed good growth of $E$. coli ethcps 2 in $\mathrm{M} 9+10 \mathrm{~g} / \mathrm{L}$ ethanol medium under anaerobic conditions without butanone input. This thus indicates that butanone exerted a toxicity effect on $E$. coli, especially with ethanol as a growth substrate. 

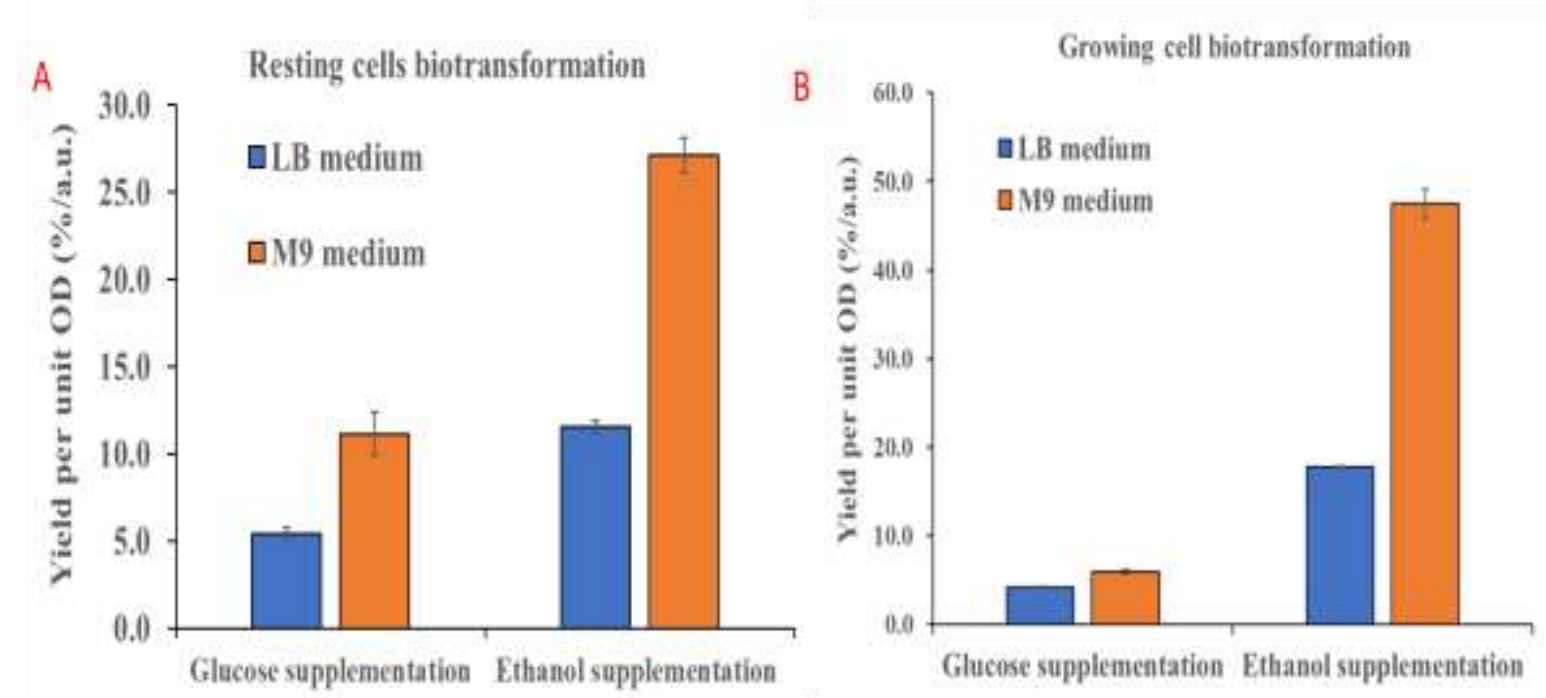

Figure 6. Effect of growth medium on biotransformation efficiency in resting and growing cells. A) Cells precultivated in M9 + $10 \mathrm{~g} / \mathrm{L}$ ethanol medium delivered higher biotransformation efficiency compared to those precultivated in $L B$ medium during resting cell biotransformation, $B$ ) Similarly, cells cultivated in $M 9+10 \mathrm{~g} / \mathrm{L}$ ethanol delivered higher yield per unit OD compared to those cultivated in LB medium during growing cell biotransformation. All experiments were conducted under anaerobic conditions at 37 oC and $225 \mathrm{rpm}$.

Growth medium influences the gene expression pattern of cells, and this may have an impact on biotransformation efficiency such as that manifested by lower expression of NADH dependent enzymes that would compete for NADH originally slated for biotransformation. In the context of this work, the growth medium effect could be present in both resting cell and growing cell biotransformation. This last segment of the work aims to probe how two common growth media (LB and M9 + $10 \mathrm{~g} / \mathrm{L}$ ethanol) in biocatalysis would influence biotransformation efficiency of butanone in resting and growing cells. Experimental results revealed that in resting cell biotransformation, cells precultivated in $\mathrm{M} 9+10 \mathrm{~g} / \mathrm{L}$ ethanol medium delivered higher biotransformation efficiency compared to those precultivated in LB medium (figure 6a). The effect was independent of whether glucose or ethanol was used as the co-substrate in resting cell biotransformation, and suggests that observed phenomenon cannot be solely attributed to "training effect" of cells precultivated in medium with ethanol supplementation. In growing cells biotransformation, cells grown in M9 $+10 \mathrm{~g} / \mathrm{L}$ ethanol medium also delivered higher biotransformation efficiency compared to those grown in LB medium (figure 6b). Overall, growth medium effect studies indicated that $\mathrm{M} 9+10 \mathrm{~g} / \mathrm{L}$ ethanol medium may be better for improving butanone biotransformation efficiency through enhancing NADH regeneration. A possible reason that could account for the observation could be lower expression of NADH dependent enzymes in cells precultivated or cultivated in $\mathrm{M} 9+10 \mathrm{~g} / \mathrm{L}$ ethanol medium. This way, there would be less competition for regenerated $\mathrm{NADH}$, and more of it could be used by cpsADH to drive butanone conversion into 2-butanol.

\section{Discussion}

Cofactor regeneration is an established technology in biocatalysis, but the search remains for new sacrificial substrate and enzymes capable of delivering enhanced cofactor regeneration at a cheaper cost [29]. In addition, the trend has been moving towards pathway-based cofactor regeneration where the cofactors could be usefully tapped for balancing the redox environment in metabolic engineering applications [30]. With the search for new sacrificial substrates, there is also a recent trend in coupling novel synthetic pathway for substrate utilization with cofactor regeneration [31] [32]. This work espouses this concept where a two-gene EUP pathway channel flux from ethanol to acetyl-CoA in central carbon metabolism, while also producing NADH useful for cofactor regeneration in whole-cell biocatalysis.

Experimental results in this study confirm that EUP could be readily integrated with cpsADH to constitute a whole-cell biocatalytic system able to convert ketone (acetophenone or butanone) to alcohol (1phenylethanol or 2-butanol) in either two-phase or single-phase biotransformation systems. Irrespective of the main biotransformation product, conversion of ketone to alcohol is not $99 \%$ as documented by many studies in biocatalysis [33] [34] [35]. HPLC data of ethanol consumption suggests that inadequate uptake of ethanol by engineered $E$. coli cells could be the underlying constraint for relatively poor conversion and product yield. Most probably, such a constraint could arises from the toxicity effect of ethanol on cells [36] [37]. Work done in bioethanol production suggests that whether at the cell level or proteome level, ethanol exerts wide spectrum toxicity effect of cells causing physiological effects such as cell envelope stress and reduced cell growth [37]. Altogether, such toxicity effects and stresses could retard the uptake of ethanol, without which conversion and product yield would be poor.

Comparative assessment of EUP and glucose dehydrogenase (GDH) system in butanone biotransformation saw enhanced biotransformation efficiency from EUP compared to GDH in whole cells provided with equal mass concentration of glucose and ethanol. Inability of whole-cell system to fully utilize glucose nevertheless precluded a more comprehensive assessment of the two NADH regeneration systems at an equimolar basis in this project. However, glucose/GDH is by far the most often used NADH cofactor regeneration system due to low cost of glucose as well as the ease of utilizing glucose [38]. Thus, it is expected that EUP could only serve specialist applications in the foreseeable future.

On the other hand, efforts in this project to address the equilibrium limited product profile from a reversible pathway saw success where higher ethanol concentration drove higher NADH regeneration and better biotransformation efficiency. Presence of reversible reactions in EUP is perhaps one critical bottleneck for allowing the pathway to deliver higher product yield. Equilibrium control of the pathway coupled with toxicity of ethanol meant that there is unlikely to be $100 \%$ consumption of ethanol that is necessary for improving conversion and product yield. Future 
effort should be directed to discovering irreversible reactions powered by enzymes from microbial species that could aid the construction of an enhanced EUP pathway.

But, the most prominent characteristic of the EUP pathway remains its ability to be tapped by cell growth processes to generate a driving force through the pathway that enhance NADH regeneration. Specifically, EUP ends in acetyl-CoA, which is a growth promoting metabolite in central carbon metabolism, and thus, allow growth processes to draw flux down the EUP pathway. Use of growth processes to deliver a driving force has delivered many success stories in metabolic engineering [39] [40], but the approach is less often used in biocatalysis. Data from this project supported the above theoretical prediction and clarified the pathway characteristics necessary for engendering growth-derived driving force for ethanol consumption and cofactor regeneration.

\section{Conclusion}

This project demonstrated that a two-gene ethanol utilization pathway (EUP) is useful for regenerating $\mathrm{NADH}$ for a ketone to alcohol biotransformation in E. coli. Furthermore, EUP is shown to be more efficient in regenerating NADH compared to the gold standard, glucose dehydrogenase. Growing cells was shown to deliver a driving force to pull ethanol to acetyl-CoA, and thereby, help regenerate more $\mathrm{NADH}$, and deliver higher alcohol yield. Finally, cultivation in M9 medium possibly reduces the expression of NADH requiring enzymes, thereby, helping to preserve the pool of NADH regenerated for supporting biocatalytic reaction, and delivering higher product yield. Overall, EUP could be used in supporting biocatalysis as well as rebalancing the intracellular redox environment in metabolic engineering applications

\section{Conflicts of interest}

The author declares no conflicts of interest.

\section{Funding}

The author thank the National University of Singapore for financial support.

\section{References}

1. P.-Y. Kim, D. J. Pollard, and J. M. Woodley, (2007) Substrate Supply for Effective Biocatalysis, Biotechnol. Prog., 23(1), doi: 10.1021/bp060314b.

2. B. Lin and Y. Tao, (2017) Whole-cell biocatalysts by design, Microb. Cell Factories, 16(1), doi: 10.1186/s12934-017-0724-7.

3. Z. Xiao et al., (2010) A Novel Whole-Cell Biocatalyst with NAD+ Regeneration for Production of Chiral Chemicals, PLoS ONE, 5(1), doi: 10.1371/journal.pone.0008860.

4. J. Wachtmeister and D. Rother, (2016) Recent advances in whole cell biocatalysis techniques bridging from investigative to industrial scale, Curr. Opin. Biotechnol. 42, pp. 169-177, doi: 10.1016/j.copbio.2016.05.005.

5. W. Ng, (2020) Cofactor regeneration could only occur if the speed of the biotransformation reaction and cofactor regeneration reaction are similar, doi: 10.6084/m9.figshare.13370321.v1.

6. W. Ng, (2020) Exploring the biotechnological potential of C2 alternative substrates in biocatalysis and metabolic engineering, doi: 10.6084/m9.figshare.12927731.v1.

7. Y. Zhang, Y. Zhao, R. Li, and J. Liu, (2021) Bioinspired NADH Regeneration Based on Conjugated Photocatalytic Systems, Sol. RRL, 5(2), p. 2000339, doi: 10.1002/solr.202000339.

8. M. K. Peers, H. S. Toogood, D. J. Heyes, D. Mansell, B. J. Coe, and N. S. Scrutton, (2016) Light-driven biocatalytic reduction of $\alpha, \beta$-unsaturated compounds by ene reductases employing transition metal complexes as photosensitizers, Catal. Sci. Technol., 6(1), pp. 169-177, doi: 10.1039/C5CY01642H.
9. S. Shah, A. V. Sunder, P. Singh, and P. P. Wangikar, (2020) Characterization and Application of a Robust Glucose Dehydrogenase from Paenibacillus pini for Cofactor Regeneration in Biocatalysis, Indian J. Microbiol., 60(1), doi: 10.1007/s12088019-00834-w.

10. J. Schüürmann, P. Quehl, F. Lindhorst, K. Lang, and J. Jose, (2017) Autodisplay of glucose-6-phosphate dehydrogenase for redox cofactor regeneration at the cell surface: Autodisplay of Glucose-6-Phosphate Dehydrogenase, Biotechnol. Bioeng, 114(8), Art. no. 8, doi: 10.1002/bit.26308.

11. Á. Mourelle-Insua, F. S. Aalbers, I. Lavandera, V. GotorFernández, and M. W. Fraaije, (2019) What to sacrifice? Fusions of cofactor regenerating enzymes with Baeyer-Villiger monooxygenases and alcohol dehydrogenases for self-sufficient redox biocatalysis, Tetrahedron, vol. 75(13), Art. no. 13, doi: 10.1016/j.tet.2019.02.015.

12. W. Qian et al., (2020) Evolution of Glucose Dehydrogenase for Cofactor Regeneration in Bioredox Processes with Denaturing Agents, ChemBioChem, 21(18), Art. no. 18, doi: 10.1002/cbic.202000196.

13. Y. Zhang, Y. Wang, S. Wang, and B. Fang, (2017) Engineering bi-functional enzyme complex of formate dehydrogenase and leucine dehydrogenase by peptide linker mediated fusion for accelerating cofactor regeneration, Eng. Life Sci., 17(9), Art. no. 9, doi: 10.1002/elsc.201600232.

14. Z. Shaked and G. M. Whitesides, (1980) Enzyme-catalyzed organic synthesis: NADH regeneration by using formate dehydrogenase, J. Am. Chem. Soc., 102(23), Art. no. 23, doi: 10.1021/ja00543a038.

15. V. I. Tishkov and V. O. Popov (2004) Catalytic mechanism and application of formate dehydrogenase, Biochem. Mosc. 69(11), Art. no. 11, doi: 10.1007/s10541-005-0071-x.

16. J. Rocha-Martín et al., (2011) New biotechnological perspectives of a NADH oxidase variant from Thermus thermophilus HB27 as NAD+-recycling enzyme, BMC Biotechnol, 11(1), 1, doi: 10.1186/1472-6750-11-101.

17. B. Geueke, B. Riebel, and W. Hummel, (2003) NADH oxidase from Lactobacillus brevis: a new catalyst for the regeneration of NAD, Enzyme Microb. Technol., 32(2), Art. no. 2, doi: 10.1016/S0141-0229(02)00290-9.

18. J. Matsumoto, M. Higuchi, M. Shimada, Y. Yamamoto, and Y. Kamio, (1996) Molecular Cloning and Sequence Analysis of the Gene Encoding the H2O-forming NADH Oxidase from Streptococcus mutans, Biosci. Biotechnol. Biochem, 60(1), Art. no. 1, doi: 10.1271/bbb.60.39.

19. T. Pongtharangkul, P. Chuekitkumchorn, N. Suwanampa, P. Payongsri, K. Honda, and W. Panbangred, (2015) Kinetic properties and stability of glucose dehydrogenase from Bacillus amyloliquefaciens SB5 and its potential for cofactor regeneration, AMB Express, 5(1), Art. no. 1, doi: 10.1186/s13568-015-0157-9.

20. A. Boldt and M. B., Ansorge-Schumacher (2020) Formate Dehydrogenase from Rhodococcus jostii $(\mathrm{RjFDH})$ - A HighPerformance Tool for NADH Regeneration, Adv. Synth. Catal., 362(19), pp. 4109-4118, doi: 10.1002/adsc.202000536.

21. B. Binay, D. Alagöz, D. Yildirim, A. Çelik, and S. S. Tükel (2016) Highly stable and reusable immobilized formate dehydrogenases: Promising biocatalysts for in situ regeneration of NADH, Beilstein J. Org. Chem., 12(1), pp. 271-277, doi: 10.3762/bjoc.12.29.

22. C. Nowak, B. Beer, A. Pick, T. Roth, P. Lommes, and V. Sieber (2015) A water-forming NADH oxidase from Lactobacillus pentosus suitable for the regeneration of synthetic biomimetic cofactors, Front. Microbiol, 6, p. 957, doi: 10.3389/fmicb.2015.00957. 
23. H. Liang et al., (2020) Constructing an ethanol utilization pathway in Escherichia coli to produce acetyl-CoA derived compounds, Bioengineering, preprint, doi: 10.1101/2020.04.14.041889.

24. S. Mordhorst and J. N. Andexer (2020) Round, round we go strategies for enzymatic cofactor regeneration, Nat. Prod. Rep., 37(10), pp. 1316-1333, doi: 10.1039/D0NP00004C.

25. F. Garzón-Posse, L. Becerra-Figueroa, J. Hernández-Arias, and D. Gamba-Sánchez (2018) Whole Cells as Biocatalysts in Organic Transformations, Mol. J. Synth. Chem. Nat. Prod. Chem., 23(6), p. 1265, doi: 10.3390/molecules23061265.

26. H. Yamamoto, N. Kawada, A. Matsuyama, and Y. Kobayashi (1999) Cloning and Expression in Escherichia coli of a Gene Coding for a Secondary Alcohol Dehydrogenase from Candida parapsilosis, Biosci. Biotechnol. Biochem, 63(6), Art. no. 6, doi: 10.1271/bbb.63.1051.

27. X. Ma et al., (2019) A standard for near-scarless plasmid construction using reusable DNA parts, Nat. Commun., 10(1), Art. no. 1, doi: 10.1038/s41467-019-11263-0.

28. W. Ng (2017) Average deviation for measuring variation in data in small samples ( $\mathrm{n}<5)$, PeerJ Inc., e3460v1, doi: 10.7287/peerj.preprints.3460v1.

29. J. Kulig, T. Sehl, U. Mackfeld, W. Wiechert, M. Pohl, and D. Rother (2019) An Enzymatic 2-Step Cofactor and Co-Product Recycling Cascade towards a Chiral 1,2-Diol. Part I: Cascade Design, Adv. Synth. Catal, 361(11), pp. 2607-2615, doi: 10.1002/adsc.201900187.

30. X. Wang, T. Saba, H. H. P. Yiu, R. F. Howe, J. A. Anderson, and J. Shi (2017) Cofactor NAD(P)H Regeneration Inspired by Heterogeneous Pathways, Chem, 2(5) pp. 621-654, doi: 10.1016/j.chempr.2017.04.009.

31. W. Ng (2020) Possibility of Tapping NADH Regenerated from Ethylene Glycol Utilization Pathway for Cofactor Regeneration, doi: 10.20944/preprints202009.0039.v1.
32. W. Ng (2020) Evaluating potential of ethanol-based NADH regeneration in supporting whole-cell biocatalysis, doi: 10.6084/m9.figshare.12932856.v1.

33. S. Sutiono, A. Pick, and V. Sieber (2021) Converging conversion - using promiscuous biocatalysts for the cell-free synthesis of chemicals from heterogeneous biomass, Green Chem., vol. 23(10), pp. 3656-3663, doi: 10.1039/D0GC04288A.

34. E. Cigan, B. Eggbauer, J. H. Schrittwieser, and W. Kroutil (2021) The role of biocatalysis in the asymmetric synthesis of alkaloids an update, RSC Adv., vol. 11(45), pp. 28223-28270, doi: 10.1039/D1RA04181A.

35. J. Britton, S. Majumdar, and G. A. Weiss (2018) Continuous Flow Biocatalysis, Chem. Soc. Rev., 47(15), pp. 5891-5918, doi: 10.1039/c7cs00906b.

36. B. Wilbanks and C. T. Trinh (2017) Comprehensive characterization of toxicity of fermentative metabolites on microbial growth, Biotechnol. Biofuels, 10, p. 262, doi: 10.1186/s13068-017-0952-4.

37. H. Cao et al., (2017) Systems-level understanding of ethanolinduced stresses and adaptation in E. coli, Sci. Rep., vol. 7(1), p. 44150, doi: 10.1038/srep44150.

38. W.-Z. Qian et al., (2020) Evolution of Glucose Dehydrogenase for Cofactor Regeneration in Bioredox Processes with Denaturing Agents, ChemBioChem, vol. 21(18), pp. 2680-2688, doi: 10.1002/cbic.202000196.

39. J. T. Ku and E. I. Lan (2018) A balanced ATP driving force module for enhancing photosynthetic biosynthesis of 3 hydroxybutyrate from CO2, Metab. Eng., 46, pp. 35-42, doi: 10.1016/j.ymben.2018.02.004.

40. W. Ng (2020) Metabolism of Non-growing Cells and Their Application in Biotransformation, doi: 10.20944/preprints202007.0402.v1

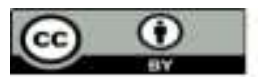

This work is licensed under Creative Commons Attribution 4.0 License

To Submit Your Article Click Here: Submit Manuscript

DOI: $10.31579 / 2766-2314 / 059$
Ready to submit your research? Choose Auctores and benefit from:

$>$ fast, convenient online submission

$>$ rigorous peer review by experienced research in your field

$>$ rapid publication on acceptance

$>$ authors retain copyrights

$>$ unique DOI for all articles

$>$ immediate, unrestricted online access

At Auctores, research is always in progress.

Learn more auctoresonline.org/journals/biotechnology-andbioprocessing 